\title{
ENSINO DE PRODUÇÃO TEXTUAL: ANÁLISE DAS PROPOSTAS APRESENTADAS EM LIVRO DIDÁTICO DESTINADO AO 5 ANO DO ENSINO FUNDAMENTAL I
}

\author{
Bianca Videira Rodrigues ${ }^{1}$, Ana Luzia Videira Parisotto ${ }^{2}$ \\ Universidade Estadual Paulista - FCT/UNESP. ${ }^{1}$ Curso de Pedagogia, Presidente Prudente - SP. ${ }^{2}$ Departamento de \\ Educação, Presidente Prudente - SP. Email: biancavideira@ @hotmail.com
}

\section{RESUMO}

Esta pesquisa é documental de base qualitativa com enfoque descritivo analítico por meio da qual pretendemos refletir sobre o ensino da produção textual mediante análise das propostas de produção de textos apresentadas no material didático: Coleção "Porta Aberta: Língua portuguesa" (10 ao 50 ano), destinado ao ensino fundamental I. Para este artigo, faremos um recorte na totalidade dos dados, apresentando somente aqueles relativos ao livro didático destinado ao quinto ano. Tal reflexão torna-se relevante por enfocar a descrição das propostas de produção de texto, bem como os gêneros textuais apresentados em uma coleção didática selecionada por professores de uma escola municipal de Presidente Prudente. Os primeiros resultados apontam que os livros da coleção estudada trazem uma diversidade de gêneros e tipos textuais, de acordo com o que asseveram os Parâmetros Curriculares de Língua Portuguesa (1997).

Palavras-chave: produção textual; livro didático, ensino de língua portuguesa, gêneros textuais, pesquisa documental.

\section{TEACHING TEXTUAL PRODUCTION: ANALYSIS OF PROPOSALS EXISTING IN A $5^{\text {TH }}$ - GRADE TEXTBOOK}

\begin{abstract}
This qualitative desk research of a descriptive analytical nature aims to reflect on the teaching of text production through the analysis of text production proposals found in "Porta Aberta: Língua portuguesa," a textbook collection for the first years of elementary school $\left(1^{\text {st }}-5^{\text {th }}\right.$ grade). This article focuses on part of the data, i.e., those relating to the $5^{\text {th }}$-grade textbook. The analysis is based on the text production proposal description as well as the text genres observed in this textbook collection selected by teachers from a public school in Presidente Prudente, Brazil. Preliminary results indicate that the textbook collection under investigation presents diverse genres and text types, in line with Brazil's National Curriculum Standards for the Teaching of Portuguese (1997).
\end{abstract}

Keywords: Text production, textbook, teaching of Portuguese, text genres, desk research. 


\section{INTRODUÇÃO}

Para o ensino e a aprendizagem da produção textual vários fatores destacam-se como relevantes, dentre eles podemos destacar a importância de se pensar a produção textual como devolução da palavra ao sujeito e como produto das interações verbais concretamente vividas pelo indivíduo (GERALDI, 1998). Assim, a formação docente para o ensino da produção textual assume papel preponderante nesse processo, uma vez que as concepções de linguagem, texto, leitura assumidas pelo docente repercutem em sua metodologia de ensino.

Um outro fator relevante diz respeito aos materiais didáticos, em especial o livro didático utilizado em sala de aula, cujo uso equivocado e sem reflexão pode propiciar atividades artificiais de produção de texto. Tal material pode ser visto como um instrumento tipicamente escolar, pois é produzido com fins educativos, apresenta conceitos e exercícios referentes a um componente curricular e, dessa forma, diverge de dicionários e obras literárias que também têm espaço na sala de aula.

Em nossa pesquisa analisamos o material didático: Coleção "Porta Aberta: Língua Portuguesa" - 10 ao 5o ano - (BRAGANÇA, 2012), destinado aos Anos Iniciais do Ensino Fundamental I. A partir dele refletimos sobre o ensino da produção textual mediante análise das propostas de produção textual apresentadas pelo material. Vale ressaltar que, para este artigo, somente serão apresentados os dados relativos ao livro didático destinado ao quinto ano do ensino fundamental I.

Os objetivos da pesquisa foram verificar qual a metodologia utilizada nos materiais didáticos para o ensino da produção de texto, observar quais são os gêneros textuais apresentados nos livros didáticos e cotejar esses dados com o que preconizam os PCNs de Língua Portuguesa (BRASIL, 1997).

\section{METODOLOGIA}

A investigação pautou-se na abordagem qualitativa de pesquisa (BOGDAN e BIKLEN, 1994; YIN, 2001), por meio de análise documental, cujos procedimentos metodológicos foram: permanente estudo e levantamento bibliográfico além de análise da coleção de livros didáticos Porta Aberta: Língua portuguesa, destinada ao ensino fundamental I, no que diz respeito ao ensino de produção textual.

A escolha do material mencionado foi com base na indicação dos professores de uma escola municipal de Presidente Prudente que selecionaram a coleção para ser utilizada durante o 
ano letivo de 2013. A escola escolheu o livro didático em consonância com o Programa Nacional do Livro Didático (PNLD).

Para Souza (1999), a utilização do Livro Didático em contexto escolar é um elemento importante a ser considerado quando falamos no processo de construção de sentidos na sala de aula e, ainda, para Tagliani (2009), apesar das periódicas avaliações, o Livro Didático ainda apresenta problemas, entretanto, se constitui num instrumento útil para o ensino de Língua Portuguesa, sendo assim é relevante desenvolver pesquisas para melhorar a discussão sobre o tema.

Os dados relativos ao livro referente ao quinto ano do ensino fundamental I foram analisados à luz do que preconizam os Parâmetros Curriculares Nacionais (BRASIL, 1997), considerando: a metodologia utilizada para o ensino da produção textual e os gêneros textuais apresentados no material.

\section{RESULTADOS}

Analisamos as propostas de produção textual no Livro Didático da Coleção Porta Aberta, destinado ao quinto ano do Ensino Fundamental I. No Quadro 1, a seguir, apresentamos as unidades que compõem o manual didático, bem como os gêneros textuais e uma descrição da atividade de produção textual proposta.

Quadro 1. O Ensino de Produção de Texto no Livro Didático 5 da Coleção Porta Aberta.

\begin{tabular}{|l|l|l|l|}
\hline UNIDADE & PÁGINA & GÊNERO TEXTUAL & ATIVIDADE PROPOSTA \\
\hline Unidade 1 & 16 e 17 & Escrita de Dicas & $\begin{array}{l}\text { Os alunos terão que acrescentar mais dicas à } \\
\text { matéria do jornal “Comece o ano letivo com } \\
\text { o pé direito!". As dicas criadas por eles e as } \\
\text { publicadas no jornal deverão ser misturadas } \\
\text { e anotadas em uma folha de papel pardo. } \\
\text { Esta folha deverá ser entregue a uma turma } \\
\text { de 4o ano que tentará descobrir quais são as } \\
\text { dicas produzidas pelos alunos. }\end{array}$ \\
\hline Unidade 2 & 46 a 48 & Crônica & $\begin{array}{l}\text { Os alunos escreverão uma crônica que será } \\
\text { reunida às crônicas produzidas pelas outras } \\
\text { duplas em um livro que será dado a uma } \\
\text { turma de 5o ano de outra escola. Num } \\
\text { primeiro momento será feito um rascunho. }\end{array}$ \\
\hline Unidade 3 & 63 e 63 & Crônica & $\begin{array}{l}\text { Na última etapa os alunos farão a revisão da } \\
\text { crônica que criaram, passarão a limpo e } \\
\text { ilustrarão a produção. }\end{array}$ \\
\hline Unidade 4 & 81 a 85 & $\begin{array}{l}\text { Escrita de Texto } \\
\text { Informativo }\end{array}$ & $\begin{array}{l}\text { PROJETO: LIXO E RECICLAGEM (PARTE 1). Os } \\
\text { alunos deverão reunir as informações } \\
\text { pesquisadas no inicio do projeto e deverão }\end{array}$ \\
\hline
\end{tabular}




\begin{tabular}{|c|c|c|c|}
\hline & & & $\begin{array}{l}\text { produzir um texto que será a base da } \\
\text { apresentação de um seminário. }\end{array}$ \\
\hline Unidade 5 & 101 a 103 & Carta de Leitor & $\begin{array}{l}\text { Os alunos escreverão cartas à revista Ciência } \\
\text { Hoje das Crianças, Recreio e Gênio, } \\
\text { solicitando reportagens de temas que } \\
\text { gostariam de ler. }\end{array}$ \\
\hline Unidade 6 & 120 e 121 & Cartaz & $\begin{array}{l}\text { Os alunos realizarão uma campanha } \\
\text { publicitária intitulada: “ Programa Atitude" e } \\
\text { farão cartazes para divulgá-la. }\end{array}$ \\
\hline Unidade 7 & 149 a 151 & Conto & $\begin{array}{l}\text { Os alunos vão usar o que aprenderam com os } \\
\text { textos desta unidade e, em duplas, } \\
\text { escreverão um conto de suspense. As } \\
\text { produções da turma serão reunidas em um } \\
\text { livro que será lido por outra turma de } 50 \text { ano } \\
\text { e, depois, doado à biblioteca da escola. }\end{array}$ \\
\hline Unidade 8 & 171 e 172 & Conto & $\begin{array}{l}\text { Os alunos farão a revisão do conto de } \\
\text { suspense e passarão a limpo. }\end{array}$ \\
\hline Unidade 9 & 185 & Poema & $\begin{array}{l}\text { Os alunos farão um texto semelhante ao de } \\
\text { Otavio Roth o professor irá expor os } \\
\text { trabalhos em um mural fora da sala de aula } \\
\text { intitulado: "Coisinhas à toa que deixam nossa } \\
\text { turma feliz. " }\end{array}$ \\
\hline Unidade 10 & 204 a 206 & Poema & $\begin{array}{l}\text { Os alunos usarão a cidade onde moram como } \\
\text { inspiração para escrever um poema. Os } \\
\text { poemas criados poderão ser divulgados na } \\
\text { escola e, depois, reunidos para formar o } \\
\text { livro: "A cidade em Verso". }\end{array}$ \\
\hline Unidade 11 & 224 a 226 & Entrevista & $\begin{array}{l}\text { PROJETO: PRODUÇÃO DE LIVRO DE } \\
\text { MEMÓRIAS E HOMENAGEM (1a PARTE). Os } \\
\text { alunos vão entrevistar pessoas mais velhas } \\
\text { da sua família ou comunidade, ouvir seus } \\
\text { relatos de lembranças e registrá-los em seus } \\
\text { cadernos. As produções serão reunidas para } \\
\text { formar um Livro de Memórias. }\end{array}$ \\
\hline Unidade 12 & 246 a 248 & Relato & $\begin{array}{l}\text { PROJETO (2a PARTE). Com os dados da } \\
\text { entrevista, os alunos escreverão um relato de } \\
\text { memórias, usando as informações da } \\
\text { entrevista de modo organizado e detalhado. }\end{array}$ \\
\hline Unidade 13 & 268 a 271 & Texto espontâneo & $\begin{array}{l}\text { PROJETO (PARTE FINAL); Os alunos irão } \\
\text { pensar na importância que tem em sua vida a } \\
\text { pessoa sobre a qual escreveu o relato e } \\
\text { escrever um pequeno texto em homenagem } \\
\text { a ela. }\end{array}$ \\
\hline
\end{tabular}




\section{DISCUSSÃO}

Diante do exposto, notamos que as atividades de produção de texto propostas no livro destinado ao quinto ano possuem diversidade de gêneros textuais por meio dos quais a criança explora muitos sentidos da própria escrita e, também da escrita do outro. Segundo Marcuschi (2008, p.155):

[...] os gêneros textuais são os textos que encontramos em nossa vida diária e que apresentam padrões sociocomunicativos característicos definidos por composições funcionais, objetivos enunciativos e estilos concretamente realizados na integração de forças históricas, sociais, institucionais e técnico.

No livro mencionado, verificamos a existência de diversos gêneros, tais como: crônica, carta, cartaz, conto, poema, entrevista, carta de leitor, relato etc que foram trabalhados com os alunos por meio de atividades que instigavam a criança a refletir, pesquisar, elaborar, questionar, refazer e corrigir o que é fundamental no processo de produção de texto.

De acordo com os Parâmetros Curriculares Nacionais de Língua Portuguesa (1997), o trabalho com produção de textos tem como finalidade formar escritores competentes e capazes de produzir textos coerentes, coesos e eficazes.

Notamos, nas atividades propostas para o ensino de produção do texto no livro estudado, a existência do trabalho com projetos que, em geral, propiciam situações de aprendizagem favoráveis para o aprendizado da escrita.

Nesse sentido, os PCNs de Língua Portuguesa (BRASIL, 1997) enfatizam que:

Os projetos são excelentes situações para que os alunos produzam textos de forma contextualizada - além do que, dependendo de como se organizam, exigem leitura, escuta de leituras, produção de textos orais, estudo, pesquisa ou outras atividades. Podem ser de curta ou média duração, envolver ou não outras áreas de conhecimento e resultar em diferentes produtos: uma coletânea de textos de um mesmo gênero (poemas, contos de assombração ou de fadas, lendas, etc.), um livro sobre um tema pesquisado, uma revista sobre vários temas estudados, um mural, uma cartilha sobre cuidados com a saúde, um jornal mensal, um folheto informativo, um panfleto, os cartazes de divulgação de uma festa na escola ou um único cartaz.

Parisotto (2004) afirma que os Parâmetros Curriculares Nacionais (1997) surgiram com a intenção de contribuir para um ensino mais eficaz da Língua Portuguesa, sintetizando os avanços apontados pela produção científica para o ensino de Língua Materna. Todavia, somente os avanços do conhecimento científico ou os materiais didáticos não garantem mudanças essenciais no ensino. É preciso que os professores envolvidos na formação dos alunos acreditem que a escola 
precisa atender às novas exigências da sociedade, no sentido de formar alunos que compreendam e utilizem adequadamente sua língua materna.

Batista; Rojo e Zúñiga (2005) destacam que o livro didático está presente cotidianamente na sala de aula e constitui um dos elementos básicos da organização do trabalho docente. Em contrapartida, o professor deve respeitar as características inerentes a cada contexto escolar, observando o que seus alunos já sabem e o que precisam aprender. Dessa forma, deve ser protagonista na preparação de suas aulas, utilizando os materiais didáticos disponíveis, de acordo com os avanços de sua turma.

Um outro aspecto relevante a ser destacado, com relação ao material didático selecionado, é que há uma preocupação com o destino dos textos produzidos pelos alunos, a fim de que não tenham apenas o professor como possível leitor. Na descrição das propostas observamos que os textos são destinados: aos alunos do quarto ano, aos alunos de quinto ano de outra escola, aos editores de revistas (Recreio, Ciência Hoje das Crianças e Gênio), dentre outros. Tal iniciativa contribui para que as propostas se tornem menos artificiais e se aproximem das práticas sociais de escrita (GERALDI, 2002; JOLIBERT, 2006; DOLZ e SCHENEUWLY, 2004).

\section{CONCLUSÃO}

A partir do estudo realizado, chegamos à conclusão de que o livro destinado ao quinto ano da Coleção Porta Aberta de Língua Portuguesa possui uma diversidade de atividades que propõem o trabalho com gêneros e tipos textuais diferentes no decorrer das unidades.

Essas atividades, por sua vez, instigam o aluno a pesquisar, refletir, estudar e analisar, a fim de pensar a proposta da atividade do livro didático e compreender o trabalho de produção de texto. Ainda faz com que o aluno passe por etapas importantes na construção de uma produção, ou seja, pensar, revisar e corrigir aquilo que não está adequado a sua escrita.

Além do exposto, notamos ser fundamental que o professor tenha um conhecimento profundo sobre o conteúdo a ser ensinado para que possa orientar e propor situações de aprendizagem mais adequadas à turma com que trabalha, elaborando adequações às atividades propostas pelos materiais didáticos utilizados.

\section{REFERÊNCIAS}

BATISTA, A. A. G; ROJO, R.; Zúñiga, N. C. Produzindo Livros Didáticos em Tempo de Mudança. In: COSTA VAL, M. G.; MARCUSCHI, B. (org). Livros Didáticos de Língua Portuguesa: letramento, inclusão e cidadania. Belo Horizonte: Autêntica/Ceale, 2005. 
BRAGANÇA, A. D. Porta Aberta: língua Portuguesa. São Paulo: FTD, 2012.

BRASIL.Parâmetros Curriculares Nacionais: Língua Portuguesa, Ministério da Educação e do Desporto, Secretaria da Educação Fundamental, Brasília: 1997.

DOLZ, Joaquim; SCHNEUWLY, Bernard. Gêneros orais e escritos na escola. Campinas: Mercado de Letras, 2004.

GERALDI, J. W. Da redação à produção de textos. In: CHIAPPINI, L. (org). Aprender a ensinar com textos de alunos. São Paulo: Cortez, 1998.

A prática da leitura na escola. In: (org). O texto na sala de aula. São Paulo: Ática, 2002.

JOLIBERT, J. et al. Além dos muros da escola: a escrita como ponte entre alunos e comunidade. 2006.

KAUFMAN, A. M. e RODRIGUEZ, M. E. Escola, leitura e produção de textos. Trad. Inayara Rodrigues. Porto Alegre: Artes Médicas, 1995.

MARCUSCHI, L. A. Produção Textual, Análise de Gêneros e Compreensão. São Paulo: Parábola Editorial, 2008.

PARISOTTO, A. L. V. Produção textual e formação docente: uma relação possível. 2004. 248 p. Tese (Doutorado em Letras) Faculdade de Ciências e Letras - UNESP, Assis, 2004.

SOUZA, D. M. Livro Didático: Arma Pedagógica? In: CORACINI, M. J. R. F. (org). Interpretação, autoria e Legitimação do livro didático: Língua Materna e Língua Estrangeira. 1ed. Campinas, SP: Pontes, 1999.

TAGLIANI, D. C. O processo de escolha do livro didático de língua portuguesa. Linguagem em (Dis)curso, Palhoça, SC, v. 9, n. 2, p. 303-320, maio/ago. 2009 